\title{
The transmission of B chromosomes in populations of Secale cereale and Secale vavilovii 1. Offspring obtained from $O B$ and $2 B$ plants
}

M. J. Puertas, F. Baeza
and A. de la Peña
Departamento de Genética, Facultad de Blologia, Universidad Complutense, 28040 Madrid, Spain.

The transmission of rye B chromosomes in experimental populations of Secale cereale and $S$. vavilovii was studied. $B$ chromosomes were introduced from $S$. cereale into $S$. vavilovii by hybridisation and backcrossing. Populations were established with plants carrying $\mathrm{OB}$ or $2 \mathrm{~B}$ chromosomes at different frequencies. Each population was isolated and allowed to fertilise by open pollination. Seeds were collected individually from each $0 B$ or $2 B$ plant. The number of $B$ chromosomes in the offspring was analysed. The results showed that there was not a direct relationship between the frequencies at which each type of pollen was formed and the offspring obtained. On the contrary, the effectiveness in fertilisation by pollen with or without $B$ chromosomes was mainly dependent on the frequencies of plants with and without $B$ chromosomes in the population; that is, pollen carrying B chromosomes became relatively more advantageous when its frequency declined. We discuss the proposal that frequency-dependent selection occurs for rye B chromosomes.

\section{INTRODUCTION}

The nature of the genetic mechanisms controlling the non-Mendelian mode of transmission of $\mathrm{B}$ chromosomes is still incompletely understood.

B chromosomes are transmitted following species-specific ruies. In rye, (Secale cereale L.), their meiotic segregation is mainly normal although some univalents can be formed (Kishikawa, 1965). At first mitotic division of both male and female gametophytes B chromosomes undergo non disjunction and preferential distribution to the nucleus giving rise to the gametes (Müntzing, 1946; Håkanson, 1948). This mode of transmission tends to accumulate $\mathrm{B}$ chromosomes in populations. The accummulation is compensated by the low fitness of plants carrying a high number of B chromosomes (Müntzing, 1963; Puertas et al., 1985). These mechanisms also explain the variation of $B$ chromosome number among the individuals within populations.

This work describes investigations into the transmission of rye B chromosomes in experimental populations in two Secale species: $S$. cereale which naturally carries $\mathrm{B}$ chromosomes, and $S$. vavilovii which does not. In the latter, B chromosomes were introduced from $S$. cereale.

\section{MATERIALS AND METHODS}

The cross-pollinating species Secale cereale var. JNK $(2 n=14)$ carrying B chromosomes, and the self-pollinating species $S$. vavilovii $(2 \mathrm{n}=14)$ were used. The latter does not naturally carry B chromosomes.

B chromosomes were introduced from $S$. cereale into $S$. vavilovii by hybridising both species and backcrossing to $S$, vavilovii during six successive generations. This line was named "Charito" (Puiertas et al., 1985)

The following experimental populations were established, each with 50 plants:

\section{Population}

$S$. cereale with 20 per cent $0 \mathrm{~B}$ +80 per cent $2 \mathrm{~B}$ plants

$S$. vavilovii with 20 per cent $0 \mathrm{~B}$ +80 per cent $2 \mathrm{~B}$ plants

$S$. cereale with 20 per cent $2 \mathrm{~B}$ +80 per cent $0 \mathrm{~B}$ plants

$S$. vaviloviii with 20 per cent $2 \mathrm{~B}$ +80 per cent $0 \mathrm{~B}$ plants

Abbreviation $8 \mathrm{C}$

$8 \mathrm{~V}$

$2 \mathrm{C}$

$2 \mathrm{~V}$

The chromosome numbers of the parent plants were determined by root tip screening before 
planting. The roots were fixed in acetic alcohol $1: 3$ and stained by the Feulgen method.

Two replicates of each population were sown in $1 \mathrm{~m}^{2}$ plots. Individuals with and without B chromosomes were distributed at random in each plot. The 8 plots were adjacent and all were planted at the same time.

At the time of anthesis each plot was covered with a thin white cotton fabric to prevent crosspollination among plots, but allowing open-pollination within each one.

Seed was collected individually from each $0 \mathrm{~B}$ or $2 \mathrm{~B}$ plant, in order to know the female parent chromosome number of the offspring. From each plot two samples were taken: about 100 seeds from $0 \mathrm{~B}$ plants and 100 seeds from $2 \mathrm{~B}$ plants.

The chromosome number of the offspring was determined in the root tips.

\section{RESULTS}

The between-replicate heterogeneity $\chi^{2}$ was non significant in all cases; and the replicate data were therefore pooled for further analysis.

Cross-pollination was expected to occurr among the plants of populations derived from $S$. cereale, while self-pollination was expected in the plants of populations derived from $S$. vavilovii due to the natural mating system of these species.

To establish the expected frequencies of the descendants of each experimental population under cross- or self-pollination, it is necessary to know the types and frequencies of gametes formed by plants carrying $2 \mathrm{~B}$ chromosomes.

The formation of male gametes mainly depend on the loss of $\mathrm{B}$ univalents during meiosis and on the frequency of directed non disjunction during pollen mitosis. Both parameters can be estimated directly from microscopic observations. The values given in table 1 are the frequences obtained by Kishikawa (1965) and Puertas et al. (1979)

Table 1 Types and frequencies of gametes produced in $S$. cereale (JNK) and $S$. vavilovii (Charito) plants with $2 \mathrm{~B}$ chromosomes. Data of pollen were obtained from direct microscopic observations, data of egg-cells were obtained from $2 \mathrm{~B} \times 0 \mathrm{~B}$ crosses

\begin{tabular}{lllllll}
\hline & & \multicolumn{8}{c}{ B chromosome number of the gametes } \\
& & 0B & 1B & 2B & 3B & 4B \\
\hline JNK & Pollen & 0.0366 & 0.2383 & 0.6329 & 0.0135 & 0.0183 \\
\multirow{4}{*}{ Charito } & Egg-cell & 0.2512 & 0.0151 & 0.7114 & 0.0 & 0.035 \\
& Pollen & 0.057 & 0.2211 & 0.7087 & 0.0119 & 0.0013 \\
& Egg-cell & 0.12 & 0.0 & 0.88 & 0.0 & 0.0 \\
\hline
\end{tabular}

The types and frequencies of female gametes have to be indirectly estimated from $2 \mathrm{~B} \times 0 \mathrm{~B}$ crosses. The values shown in table 1 correspond to a number of crosses made during several years in our laboratory which are not previously published.

It has to be noted that in all tables presented in this work gametes or individuals with more than 4B chromosomes were not considered since their frequency was always very low. These classes were added to the 4B one.

Once the female and male gamete frequencies were known in both species, the expected frequencies for the different types of descendants were calculated for each experimental population. These frequencies are shown in table 2. Obviously, the values calculated for populations derived from $S$. cereale were different from the $8 \mathrm{C}$ and $2 \mathrm{C}$ populations, since they were estimated assuming crosspollination. However, the values estimated for populations derived from $S$. vavilovii were the same for both $8 \mathrm{~V}$ and $2 \mathrm{~V}$ populations, since they were estimated assuming self-pollination. In this case, the seeds produced by a plant do not depend on the other plants of the population.

Table 2 Frequencies of descendants expected in the experimental populations. In $S$. cereale (JNK) these frequencies were calculated for cross-pollination, in $S$. vavilovii (Charito) they were calculated for self-pollination

\begin{tabular}{|c|c|c|c|c|c|c|}
\hline Population & $\begin{array}{l}\text { Female } \\
\text { parent }\end{array}$ & OB & $1 \mathrm{~B}$ & $\begin{array}{c}\text { Offspring } \\
\text { 2B }\end{array}$ & $3 B$ & $4 B$ \\
\hline \multirow[t]{2}{*}{ JNK 8C } & 0B & $0 \cdot 2293$ & $0 \cdot 2389$ & 0.5063 & 0.0108 & 0.0146 \\
\hline & $2 \mathrm{~B}$ & 0.0576 & 0.0635 & $0 \cdot 2939$ & 0.1775 & 0.4075 \\
\hline \multirow[t]{2}{*}{ JNK 2C } & OB & 0.8073 & 0.0597 & $0 \cdot 1266$ & 0.0027 & 0.0037 \\
\hline & $2 B$ & $0 \cdot 2028$ & 0.0272 & 0.6070 & 0.0451 & $0 \cdot 1179$ \\
\hline \multirow[t]{2}{*}{ Charito } & OB & $1 \cdot 00$ & & & & \\
\hline & $2 B$ & 0.0068 & 0.0265 & 0.1353 & $0 \cdot 1960$ & 0.6354 \\
\hline
\end{tabular}

Table 3 shows the descendants observed in $8 \mathrm{C}$ and $2 \mathrm{C}$ populations obtained on $\mathrm{OB}$ and $2 \mathrm{~B}$ plants, and the values expected according to the frequencies calculated in table 2 . It can be seen that the differences between observed and expected values are very large. $\chi^{2}$ values were highly significant in all cases.

Table 4 shows the same for populations derived from $S$. vavilovii: $8 \mathrm{~V}$ and $2 \mathrm{~V}$. Also in this case the differences between observed and expected values were remarkable.

The significant differences between observed and expected values in the descendants indicate that the gametes involved in fertilisation were not 
Table 3 Offspring obtained from populations derived from $S$. cereale and values expected from cross-pollination. All $\chi^{2}$ tests were significant

\begin{tabular}{|c|c|c|c|c|c|c|c|c|}
\hline \multirow{2}{*}{$\frac{\text { Population }}{\text { JNK 8C }}$} & \multicolumn{2}{|c|}{$\begin{array}{l}\text { Female } \\
\text { parent }\end{array}$} & OB & $1 \mathrm{~B}$ & $\begin{array}{l}\text { Offspring } \\
\text { 2B }\end{array}$ & $3 \mathrm{~B}$ & $4 B$ & Total \\
\hline & OB & obs. & 107 & 7 & 58 & 6 & 33 & 210 \\
\hline & & exp. & $48 \cdot 15$ & $50 \cdot 17$ & $106 \cdot 32$ & $2 \cdot 27$ & 3.06 & \\
\hline & $2 \mathrm{~B}$ & obs. & 28 & 5 & 71 & 13 & 103 & 220 \\
\hline & & exp. & $12 \cdot 67$ & 13.97 & $64 \cdot 66$ & $39 \cdot 05$ & $89 \cdot 65$ & \\
\hline \multirow[t]{4}{*}{ JNK $2 \mathrm{C}$} & OB & obs. & 144 & 10 & 54 & 4 & 8 & 220 \\
\hline & & exp. & $177 \cdot 61$ & $13 \cdot 13$ & $27 \cdot 85$ & 0.60 & 0.81 & \\
\hline & $2 B$ & obs. & 31 & 2 & 81 & 11 & 56 & 181 \\
\hline & & exp. & $36 \cdot 71$ & 4.92 & $109 \cdot 87$ & $8 \cdot 16$ & $21 \cdot 33$ & \\
\hline
\end{tabular}

Table 4 Offspring obtained from populations derived from $S$. vavilovii and values expected from self-pollination. All $\chi^{2}$ tests were significant

\begin{tabular}{|c|c|c|c|c|c|c|c|c|}
\hline Population & $\begin{array}{l}\text { Fen } \\
\text { par }\end{array}$ & $\begin{array}{l}\text { ale } \\
\text { nt }\end{array}$ & OB & 1B & $\begin{array}{l}\text { Offspring } \\
\text { 2B }\end{array}$ & 3B & $4 B$ & Total \\
\hline \multirow[t]{4}{*}{ Charito $8 \mathrm{~V}$} & $0 \mathrm{~B}$ & obs. & 83 & 0 & 11 & 4 & 50 & 148 \\
\hline & & exp. & 148 & & & & & \\
\hline & $2 \mathrm{~B}$ & obs. & 3 & 1 & 15 & 13 & 148 & 180 \\
\hline & & exp. & $1 \cdot 22$ & $4 \cdot 77$ & $24 \cdot 35$ & $35 \cdot 28$ & $114 \cdot 37$ & \\
\hline \multirow[t]{4}{*}{ Charito 2V } & $0 \mathrm{~B}$ & obs. & 201 & 0 & 10 & 1 & 26 & 238 \\
\hline & & exp. & 238 & & & & & \\
\hline & $2 \mathrm{~B}$ & obs. & 2 & 1 & 34 & 5 & 92 & 134 \\
\hline & & exp. & 0.91 & $3 \cdot 55$ & $18 \cdot 13$ & $26 \cdot 26$ & $85 \cdot 14$ & \\
\hline
\end{tabular}

in the same frequencies as those expected according to direct pollen observations and egg-cell estimations. In view of this discrepancy it is therefore necessary to estimate the types and frequencies of gametes that actually took part in fertilisation in each population.

The descendants obtained on $0 \mathrm{~B}$ plants indicate the types and frequencies of pollen involved in fertilisation, since $0 \mathrm{~B}$ plants produce only gametes without Bs, and the distribution of Bs among their descendants is a direct reflection of the types of pollen that actually fertilised them.

Assuming that the mass of pollen nuclei that fertilised $0 \mathrm{~B}$ plants was the same that fertilised $2 \mathrm{~B}$ plants, then the types and frequencies of female gametes actually fertilised can also be estimated. Let $p, q, r, s, t$ be the frequencies of $0,1,2,3$ and 4B carrying female gametes to be estimated; let $p^{\prime}$, $q^{\prime}, r^{\prime}, s^{\prime}, t^{\prime}$ be the the frequencies of the corresponding male gametes (which are known from descendants of $0 \mathrm{~B}$ plants), and let $P, Q, R, S, T$ be the frequencies of descendents with $0,1,2,3$ and $4 \mathrm{~B}$ obtained in the population. The frequencies of female gametes can thus be easily estimated, since $p p^{\prime}=P ; p q^{\prime}+p^{\prime} q=Q ; p r^{\prime}+q q^{\prime}+r p^{\prime}=R$, etc.

The values estimated for female and male gametes formed (based on table 1) and actually fertilised in populations derived from $S$. cereale are shown in table 5 .

Table 6 shows these values calculated for populations derived from $S$. vavilovii. In this case female fertilised gametes cannot be estimated due to selfpollination. The assumption that the mass of pollen that fertilised $0 \mathrm{~B}$ plants was the same that fertilised $2 \mathrm{~B}$ plants cannot be made.

The values estimated in tables 5 and 6 were used to obtain the ratios between the gametes with Bs and without Bs formed and fertilised in each population. The ratios have been represented in a Dewitt graph (figure 1)

\section{DISCUSSION}

\section{Populations derived from S. cereale}

The deviation between observed values of descendants obtaine in $8 \mathrm{C}$ and $2 \mathrm{C}$ populations and those expected assuming cross-pollination (table 3 ) was very large. For example, in the $8 \mathrm{C}$ population the descendants without Bs collected on $0 \mathrm{~B}$ plants were more than double the number expected. A percentage of self-pollination could be supposed to account for this deviation. However, this seems not to be the case due to two reasons: (a) in this 
Table 5 Frequencies of gametes formed and taking part in fertilisation in populations derived from $S$. cereale

\begin{tabular}{|c|c|c|c|c|c|c|c|c|}
\hline \multirow{3}{*}{$\begin{array}{l}\text { Number } \\
\text { of } \mathrm{Bs}\end{array}$} & \multicolumn{4}{|c|}{$8 \mathrm{C}$ population } & \multicolumn{4}{|c|}{ 2C ponulation } \\
\hline & \multicolumn{2}{|c|}{ total pollen } & \multicolumn{2}{|c|}{ egg-cells } & \multicolumn{2}{|c|}{ total pollen } & \multicolumn{2}{|c|}{ egg-cells } \\
\hline & formed & fertil. & formed & fertil. & formed & fertil. & formed & fertil. \\
\hline OB & 0.2293 & 0.5095 & 0.2512 & $0 \cdot 2498$ & 0.8074 & 0.6545 & 0.2512 & $0 \cdot 2617$ \\
\hline $1 \mathrm{~B}$ & 0.2389 & 0.0333 & 0.0151 & 0.0282 & 0.0597 & 0.0454 & 0.0151 & 0.0 \\
\hline 2B & 0.5063 & $0 \cdot 2762$ & $0 \cdot 7114$ & 0.4962 & $0 \cdot 1266$ & $0 \cdot 2455$ & 0.7114 & 0.5856 \\
\hline $3 B$ & 0.0108 & 0.0286 & $0 \cdot 0$ & 0.0544 & 0.0027 & 0.0182 & 0.0 & 0.0449 \\
\hline $4 B$ & 0.0146 & $0 \cdot 1571$ & 0.0360 & $0 \cdot 1714$ & 0.0036 & 0.0364 & 0.0360 & 0.1078 \\
\hline
\end{tabular}

Table 6 Frequencies of pollen formed and taking part in fertilisation in populations derived from $S$. vavilovii

\begin{tabular}{|c|c|c|c|c|}
\hline \multirow{3}{*}{$\begin{array}{l}\text { Number } \\
\text { of Bs }\end{array}$} & \multicolumn{2}{|c|}{$8 \mathrm{~V}$ population } & \multicolumn{2}{|c|}{$2 \mathrm{~V}$ population } \\
\hline & total & pollen & total & pollen \\
\hline & formed & fertilised & formed & fertilised \\
\hline OB & $0 \cdot 2456$ & 0.5608 & $0 \cdot 8114$ & 0.8445 \\
\hline $1 \mathrm{~B}$ & 0.1769 & 0.0 & 0.0442 & 0 \\
\hline $2 \mathrm{~B}$ & 0.5670 & 0.0743 & 0.1417 & 0.0420 \\
\hline $3 \mathrm{~B}$ & 0.0095 & 0.0270 & 0.0024 & 0.0042 \\
\hline $4 B$ & 0.0010 & 0.3378 & 0.0003 & $0 \cdot 1092$ \\
\hline
\end{tabular}

population 4B descendants were obtained with a much higher frequency than expected and, (b) in the $2 \mathrm{C}$ population many less $0 \mathrm{~B}$ descendants were obtained from $0 \mathrm{~B}$ plants than expected. If selfpollination occurred many more would have been found. Therefore, even accepting that a percentage of self-pollination can occurr in these populations, this was evidently not the main cause of the difference between observed and expected offspring.

In order to find an explantion for the results, we estimated the frequencies of the male and female gametes actually involved in fertilisation, following the method previously described (table 5).

The estimates for fertilised female gametes with $0 \mathrm{~B}$ coincide in the $8 \mathrm{C}$ and $2 \mathrm{C}$ population with the frequencies of $0 \mathrm{~B}$ gametes formed estimated from $0 \mathrm{~B} \times 2 \mathrm{~B}$ crosses (table 5). This is a consistent result, since no variation was expected in the types of female gametes depending on different populations. That is, the ratio between female gametes with Bs/without Bs was constant in all types of estimates and populations. However a difference was observed in $2 \mathrm{~B}$ and $4 \mathrm{~B}$ classes between the frequency of female gametes formed and fertilised.
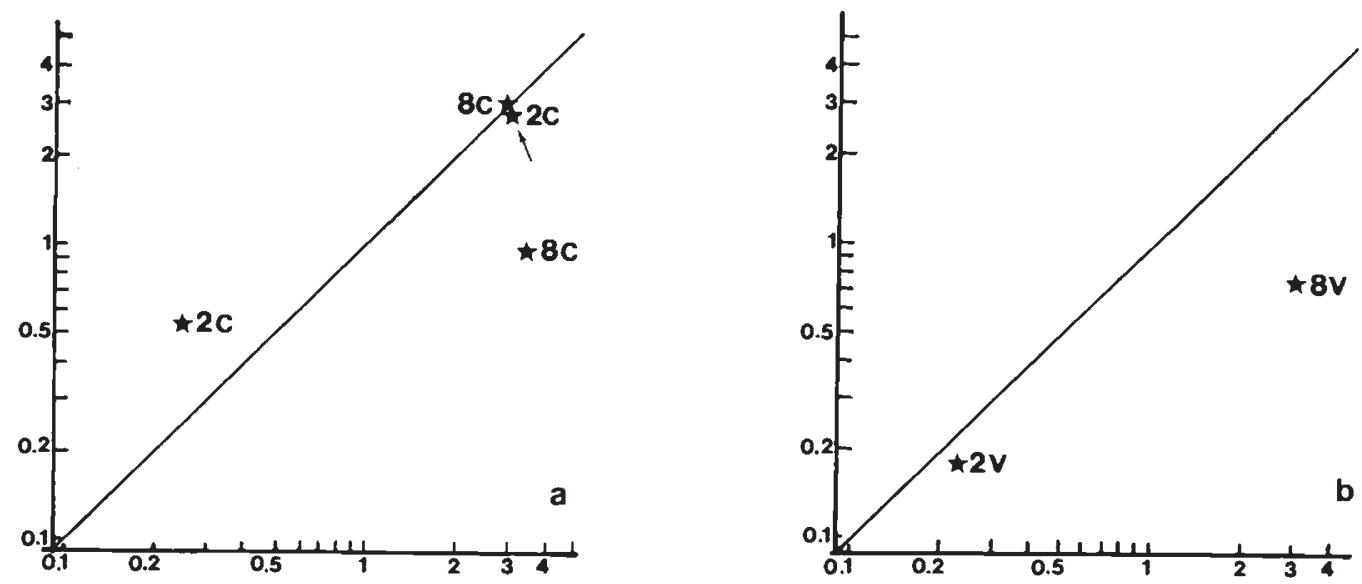

Figure 1 Graphs representing the deviation from random fertilisation in the four studied populations. Abscissae are the ratios between gametes with Bs/without Bs formed in the parental population. Ordinates are the ratios between gametes with Bs/without Bs really fertilised. The scale is logarithmic. a. Populations derived from $S$. cereale. Female gametes (arrow) fertilised at the same frequency that they were formed. Male gametes carrying Bs were more effective than expected in population $2 \mathrm{C}$ and less effective in $8 \mathrm{C}$. $b$. The same in populations derived from $S$. vavilovii. 
This is because the estimation has to be considered as only approximate, since the estimation of $q(1 \mathrm{~B})$ depend on $p(0 \mathrm{~B})$, the estimation of $r(2 \mathrm{~B})$ depend on $\mathrm{p}$ and $\mathrm{q}$, and so on; so that the errors are cummulative. However, it seems that for $0 \mathrm{~B}$ female gametes the estimated frequencies can be accepted.

In the case of the male gametes large differences were observed between the frequencies of pollen B-types formed and the frequencies actually taking part in fertilisation, but they are of different direction in the $8 \mathrm{C}$ and $2 \mathrm{C}$ populations.

In the $8 \mathrm{C}$ population in which there were 80 per cent plants with $\mathrm{Bs}$, much pollen with Bs was formed, but the frequency of $0 \mathrm{~B}$ pollen taking part in fertilisation was double the amount expected. In the case of $2 \mathrm{~B}$ pollen the amount involved in fertilisation was only half of the amount actually produced. Therefore, when there are many B chromosomes in the population pollen without Bs becomes advantageous, and pollen with Bs disadvantageous.

On the contrary, in the $2 \mathrm{C}$ population in which there were 20 per cent plants with $\mathrm{Bs}$, pollen without Bs was involved in fertilisation at about $\frac{3}{4}$ of the frequency at which it was formed, while $2 \mathrm{~B}$ pollen took part in fertilisation at double the frequency of its formation. Therefore, when there are few Bs in the population, pollen with Bs becomes advantageous and pollen without Bs disadvantageous.

The deviation from randomness can be represented in a Dewitt graph (fig. 1a), the abscissae are the ratios between pollen with Bs/without Bs formed in the parental populations; the ordinates are the ratios between pollen with Bs/without Bs taking part in fertilisation. In the case of female gametes these ratios coincide. However, a competition between the different types of pollen is clearly manifested: pollen with Bs becomes advantageous when its frequency is low and vice versa.

\section{Populations derived from S. vavilovii}

Table 4 shows that the offspring obtained differed significantly from expectations assuming total selfpollination.

The mating system of this species can be considered as totally self-pollinating, since a complete lack of variation for many isoenzyme loci was demonstrated (Perez de la Vega and Allard, 1984). However, our results are a proof that selfing was not complete in this experiment since $0 \mathrm{~B}$ plants gave rise to descendants with $\mathrm{Bs}$, and it seems evident that the cross-pollination detected is due to $\mathrm{B}$ chromosomes.
The frequencies of the different pollen B-types involved in fertilisation were also estimated for the $8 \mathrm{~V}$ and $2 \mathrm{~V}$ populations (table 6). Female gametes actually fertilised cannot be estimated in this case due to selfing. In $S$. cereale we supposed that the mass of pollen involved in fertilising $0 \mathrm{~B}$ plants was the same that which fertilised the $2 \mathrm{~B}$ plants, but this assumption cannot be made for $S$. vavilovii.

In population $8 \mathrm{~V}$, that is with many $\mathrm{Bs}$, we can observe that $0 \mathrm{~B}$ pollen was involved in fertilisation at double the frequency at which it was produced, while pollen with Bs took part in fertilisation at a frequency which was much lower than that at which it was formed. Therefore both in $S$. cereale and $S$. vavilovii when there are many Bs in the population pollen without Bs becomes advantageous.

In the $2 \mathrm{~V}$ population there is almost no difference between the types of pollen formed and the types involved in fertilisation, i.e., in this case the advantage of pollen carrying Bs is not as evident as in $S$. cereale. However it has to be noted that gametes carrying Bs have broken the mating system of the species. That is, pollen carrying Bs was sufficiently competitive to take part in fertilisation in about 15 per cent of the cases, when it was expected to fertilise none due to self-pollination. These data are represented in figure $1 \mathrm{~b}$.

Two main conclusions can be drawn from the data presented in this paper. First: the effectiveness of pollen carrying B chromosomes is mainly dependent on the frequency of plants with and without Bs in the population; pollen carrying Bs becomes advantageous when its frequency declines. Second: this behaviour is dependent on B chromosomes themselves, since the competence among the different types of pollen is comparable in both species $S$. cereale and $S$. vavilovii.

This behaviour could be explained assuming a pollen-style interaction, in such a way that the mating ability of each type of pollen would depend on this interaction. That is, if the style belongs to a $2 \mathrm{~B}$ plants, a $0 \mathrm{~B}$ pollen would have a higher probability being involved in fertilisation, and conversely, if the style belongs to a $0 \mathrm{~B}$ plant a pollen carrying Bs would have the higher opportunity. Therefore, in a population with a high frequency of OB plants, pollen with Bs would be advantageous, and vice versa. Then, the equilibrium for B chromosomes polymorphism could be established by a frequency-dependent selection.

Finally, it has to be noted that pollen carrying $1 \mathrm{~B}$ always took part in fertilisation with a lower frequency than expected, while pollen with 3 or 4 Bs was involved with a frequency higher than 
expected in all populations (tables 5 and 6). In other words, pollen with 3 or 4 Bs was advantageous irrespective of the frequency of B chromosomes in the population.

This can be explained as follows: in the present work the frequencies of pollen types involved in fertilisation were calculated from descendants collected on $0 \mathrm{~B}$ plants. If we suppose than on $\mathrm{OB}$ style, pollen with Bs is advantageous due to pollenstyle interactions, the higher the number of $\mathrm{Bs}$ in pollen, the higher the advantage of such pollen. Then, pollen with many Bs lying on $0 \mathrm{~B}$ styles will be very effective, despite the fact that the zygotes will carry many B chromosomes, and therefore, they will have a low fitness.

This behaviour, which can be qualified as parasitic, together with the fact that the advantage of $B$ carrying gametes seems to be only of benefit to the B chromosomes themselves, makes clear that B chromosomes can be considered as selfish DNA. We believe that this idea first proposed by Jones (see Jones, 1985 for a review) can be definitively accepted.

Acknowledgements This work has been supported by a grant of the Comisión Asesora de Investigación Cientifica y Técnica of Spain.

\section{REFERENCES}

JONES, R. N. 1985. Are B chromosomes selfish? In The Evolution of Genome Size. Cavalifer-Smith (ed.), John Wiley and Sons Ltd. pp. 397-425.

KISHIKAWA, H. 1965. Cytogenetic studies of B chromosomes in rye, Secale cereale in Japan. Agr, Bul. Saga Univ., 21, $1-81$.

HÅKANSON, A. 1948. Behaviour of accessorry chromosomes in the embryo sac. Hereditas, 34, 35-39.

MÜNTZING, A. 1946. Cytological studies of extra fragment chromosomes in rye III. The mechanism of non-disjunction at the pollen mitosis. Hereditas, 32, 507-509.

MÜNTZING, A. 1963. Effects of accessory chromosomes in diploid and tetraploid rye. Hereditas, 49, 361-426.

PEREZ DE LA VEGA M. AND ALLARD R. W. 1984. Mating system and genetic polymorphism in populations of Secale cereale and Secale vavilovii. Can. J. Genet. Cytol., 26, 308-317.

PUERTAS, M. J. DIEZ, M. AND CARMONA R. 1979. Rye B chromosome behaviour at first and second pollen mitosis and its relationship with another maturity. Theor. Appl. Genet., 54, 65-68.

PUERTAS, M. J., ROMERA, F. AND DE LA PEÑA, A. 1985. Comparison of B chromosome effects on Secale cereale and Secale vavilovii. Heredity, 55, 229-234. 